\title{
Emigración de catalanes a Cuba a comienzos del Siglo XIX
}

\author{
MARIA DOLORES PEREZ MURILLO
}

\section{EMIGRACION DE CATALANES A CUBA A COMIENZOS DEL XIX}

Esta investigación forma parte de un conjunto más amplio, referido a la emigración legal de peninsulares a la Isla de Cuba, según los permisos o licencias de embarque que, para el siglo XIX, se conservan en el ARCHIVO GENERAL DE INDIAS de Sevilla en las Secciones de Santo Domingo y Ultramar.

Este trabajo podemos dividirlos en dos apartados, el primero de ellos versa sobre el análisis de las fuentes documentales consultadas con todas sus posibilidades y limitaciones, y por otro lado, los caracteres específicos del movimiento migratorio catalán al Caribe, concretamente, la isla de Cuba.

\section{EL MATERIAL DOCUMENTAL CONSULTADO. POSIBILIDADES Y LIMITACIONES}

La elaboración del presente artículo ha estado basado..., en su totalidad, en fuentes documentales procedentes de las Secciones de Ultramar y Santo Domingo del Archivo de Indias. Hemos consultado 44 legajos, pero el presente artículo se encuentra documentado en el detallado análisis de 35 de los mismos (1).

El número de licencias de embarque contenidas en cada legajo, a nivel general, es aleatorio, dándose un máximo de 184 hasta un míni-

(1) Los Legajos consultados para elaborar este capitulo, todos ellos específicos sobre emigración, se encuentran en el ARCHIVO DE INDIAS Secciones de Ultramar, desde el Legajo 326 al 364, y en la de Santo Domingo desde el 2.200 al 2.206. 
mo de 40 permisos por Legajo, no obstante, podemos calcular una media de 90 licencias de embarque por cada uno de los legajos consultados, lo que supondría una cifra total de emigrantes legales peninsulares a Cuba de 4.000 individuos, siendo el total de catalanes computados para los primeros 30 años del siglo XIX de 2.475 personas.

Cada licencia de embarque, comúnmente, estaba acompañada de los siguientes documentos.

A.. En primer lugar, una instancia dirigida al Rey, la cual nos ofrece dos modalidades, según se trate de un emigrante catalán o del norte de la península. La instancia de los catalanes suelen ser personal y nominativa, es decir, la persona que quiere emigrar, aunque sea menor, aparece como el único solicitante, solicitante por antonomasia, sin embargo, entre las gentes del norte de España cuando el que desea emigrar es joven y tiene padres o tutores, es el cabeza de familia el que solicita del gobierno conceda permiso para que marche a la Isla de Cuba su hijo o tutelado. Esta apariencia, meramente formal y burocrática, puede que, hipotéticamente, nos apunte hacia la existencia de unos más fuertes vínculos de dependencia familiar entre los vascos-navarros, cántabros, y asturianos, al menos, comparativamente hablando y en este caso específico. Estas instancias nos aportan datos, de singular importancia, como son:

-Exactitud geográfica en cuanto al lugar de origen del emigrante, casi podemos hablar de una extremada precisión localista y comarcal. Este dato de precisión geográfica ofrece múltiples posibilidades para hacer estudios de historia local, estudios que profundicen en las motivaciones socio-económicas, estructurales y coyunturales del fenómeno emigratorio en una comarca determinada.

-En estas instancias suele constar, igualmente, la edad y el estado civil del emigrante. Son estos datos los que nos permiten el análisis cualitativo, y las motivaciones inminentes de la realidad emigratoria. Emigración de jóvenes y adolescentes, mayoritariamente solteros, en la plenitud de sus fuerzas físicas y en buena actitud de aprendizaje y progreso que les conduce a Cuba, motivados por la idea de hacer fortuna.

-Estas instancias en algunas ocasiones, las menos frecuentes, aluden lacónicamente a la profesión del emigrante. La falta de continuidad en este dato nos ha impedido verificar la evaluación precisa y cuantitativa de la extracción socio-profesional de cuantos emigraron a Cuba.

-Por último, en cada instancia existe una justificación de que el individuo que desea emigrar a Cuba, no va a convertirse en elemento desarraigado, y consecuentemente conflictivo, pues siempre hay 
alguien en la Isla, ya establecido, pariente o amigo, que lo reclama y promete colocarlo en su negocio. Este era un requisito indispensable para obtener la concesión de embarque, la cual podía ser denegada si no se acreditaba el reclamo desde Cuba. También en todas las instancias se especifica el lugar de destino y, casi siempre, la actividad que desempeñará el emigrante.

B. Otro documento, que acompaña a la solicitud de licencia de embarque, es el consentimiento, verificado ante notario, del padre, tutor, familiar más cercano, o cónyuge del que desea emigrar si es casado. En el caso del emigrante soltero el consentimiento, normalmente otorgado por los ascendientes, o en su defecto, por tutores o familiares próximos, no presenta limitación temporal alguna. Sin embargo, los casados deben presentar la conformidad de su esposa en la que se haga constar, que el emigrante no abandona el hogar conyugal, siendo dicha conformidad un requisito, sine qua non, para emprender la marcha. El hombre casado emigra con una limitación temporal, tan sólo por dos o tres años, siempre que, expirado este plazo, no presente otro consentimiento de su cónyuge que le permita prolongar su presencia en la Isla otros cuantos años más, y así indefinidamente.

Este tipo de documento sirve al investigador para comprobar el nivel de arraigo familiar de un individuo a su país de origen. Igualmente, en muchos de estos consentimientos aparece especificada la profesión del que los otorga, lo cual nos permite establecer, a grandes rasgos, la extracción social del emigrante, y el trasvase sectorial, casi generacional, que el fenómeno migratorio significa.

C. La licencias de embarque van acompañadas también de certificados de buena conducta, expedidos por el Ayuntamiento del lugar de origen, en donde se suele acreditar la fidelidad del individuo al régimen político reinante. Así pues, durante el reinado de Fernando VII nos encontramos con individuos que alegan como mérito para poder obtener el permiso de embarque, según la coyuntura, la fidelidad a la Constitución, durante el Trienio Constitucional o, por el contrario, la lucha contra el constitucionalismo durante las épocas absolutistas de $1814-1820$ y de $1823-1833$.

D. Las licencias de embarque llevan adjuntas las Partidas del Bautismo, siendo las de los catalanes, escritas en lengua catalana, las más precisas y abundantes en datos para configurar la fisonomía local, familiar y social del emigrante. En la mayoría de estas partidas bautismales aparece el origen geográfico y profesión de los padres y abue- 
los, e incluso, la profesión de algunos otros familiares o testigos presentes en el acto social y religioso del bautismo. Estas partidas pueden ser muy útiles al historiador local para investigar los movimientos de población dentro de una misma región o comarca, junto con el cambio o continuidad, de carácter familiar y generacional, en una determinada actividad profesional.

E. Por último, un documento, de capital importancia, que acompaña a algunas solicitudes de permiso de embarque, es la carta familiar-privada, ese escrito, íntimo y entrañable, pese a su rutina, que nos permite transcender la realidad humana y cualitativa del fenómeno emigratorio, que nos permite traspasar el frío dato estadístico o la fría instancia convencional y burocrática, para, de esta forma, adentrarnos en el pensar y en el sentir de hombres anónimos, de hombres sin historia, sin los cuales no tienen sentido las Ciencias Humanas. En definitiva, estas cartas permiten acercarnos, someramente, al mundo de las Mentalidades.

Como valoración sobre el material documental, en el que basamos el presente artículo, éste nos permite un estudio del fenómeno migratorio catalán, y en general para toda la península, más cualitativo que cuantitativo, pues los valores numéricos anteriores a 1815 se encuentran incompletos, sobre todo el periodo de la guerra contra los franceses, 1808-1814. Es, a partir de 1815 cuando hallamos series numéricas más completas. Para el año de 1823, fin del "Trienio Constitucional" y comienzo de la "Década Ominosa", apenas hemos contabilizado licencias de embarque, ya que es muy posible que el fuerte control represivo, ejercido sobre la población española por el aparato estatal, frustrara cualquier intento, más o menos legal, de salir fuera del país. Son los años de 1827 a 1832, ambos inclusive, los que registran el máximo de oleadas migratorias hacia Cuba, siendo los catalanes el grupo más numeroso. Igualmente, en estos años, sobre todo en 1828 y 1829 , la política anti-española que se vivía en México impulsará a muchos comerciantes penínsulares, prioritariamente catalanes, con intereses comerciales, originariamente en México, a buscar un nuevo mercado, ya famoso y próspero, como es el cubano y, sobre todo, el habanero. También era coyuntura favorable a la inmigración cubana la crisis política emancipadora en la que se encuentra inmerso el continente suramericano, independencia que orienta irremediablemente a los peninsulares, comerciantes y realistas, hacia el mercado cubano, más seguro y prometedor, dada la fidelidad de la Isla a la Corona española. 


\section{CARACTERISTICAS DE LA EMIGRACION CATALANA A CUBA}

Son los años de 1827 y 1828 los de mayor afluencia catalana a Cuba, pues los catalanes van a llegar a significar el 72 por ciento del total de inmigrantes peninsulares. Esta coyuntura no es extraña, ya que en la década de los veinte del siglo XIX, y sobre todo en 1827, se está viviendo en Cataluña una gran depresión económica, como magistralmente señala Vicens Vives:

El segundo ciclo depresivo que se extiende desde 1821 a 1830, acarrea gravísimas oscilaciones, como la crisis de 1827, repercusión regional de la crisis europea que tuvo lugar dos años antes. Prosiguen su caída vertical los precios del mercado... El fracaso del utillaje mental de la Restaứación es completo en el campo económico. La falta de reacción de la economía del país depende de las orientaciones de un Gobierno que ha intentado prescindir de la burguesía y de los campesinos y satisfacer los deseos de la aristocracia y de los grandes propietarios (2).

La emigración catalana a Cuba nos ofrece una serie de particularidades que hemos agrupado en los siguientes apartados:

1. Los lugares de origen de los emigrantes, dentro de la región catalana, se ubican en la zona costera que, de norte a sur, van desde Bagur en Gerona hasta Tarragona. De toda esta área geográfica, los lugares que aportan un mayor número de emigrantes son: Mataró, Barcelona, Sitges, Vilanova y Geltrú, Arenys de Mar, Canet de Mar, etc. El origen costero del emigrante nos revela su vinculación, directa o indirectamente, al mundo del comercio ultramarino.

2. Casi todos los catalanes que emigran a la Isla de Cuba se dedicarán a la actividad comercial, bien individualmente, o bien constituyéndose en sociedad con otros paisanos.

3. La extracción y origen social del emigrante catalán, en relación con la profesión de sus padres, es heterogénea.

-Gran parte de los emigrantes, que marchan a Cuba para dedicarse a la actividad comercial, son hijos de labradores. Se observa, pues,

(2) VICENS VIVES, Jaume. LOS CATALANES EN EL SIGLO XIX. Alianza Editoriel. Enciclopedia Catalana, Biblioteca de Cultura Catalana número 3. Madrid-Barcelona, 1986. Pág. 155. 
un trasvase sectorial de carácter generacional, pues la agricultura catalana se ve sumida en una profunda crisis desde las guerras con los franceses hasta la década de los 30 del siglo XIX en que comienza a normalizarse:

No obstante, los años que siguieron a la guerra contra el francés no fueron precisamente los más favorables para una exaltación de la agricultura. Cataluña había sido durante seis largos años teatro de prolongadas operaciones militares, y la consiguiente devastación, unida al abandono de las masías por amos y trabajadores, convirtió la tierra en un yermo. La recuperación fue dificilísima, cuando más habida cuenta que desde 1812 cayeron verticalmente los precios de todas las cosas, y este ambiente de crisis no era en modo alguno favorable a un resurgimiento..., los trabajos de investigación original que han llegado a nuestras manos demuestran que el campo de Cataluña no registró una verdadera expansión hasta fines del año de 1828 , o sea en un momento en que también la industria textil resurgía tras el tremendo impacto de la guerra y de la crisis (3).

-Otros individuos que emigran se encuentran ligados al sector primario en la actividad pesquera, son hijos de pescadores y marineros.

-Muchos emigrantes ejercen en Cataluña oficios especializados, relacionados con el mundo del comercio, y complementarios a la actividad comercial que desempeñarán en Cuba. Existen, en este sentido, múltiples casos de individuos que trabajan como cuberos, toneleros, panaderos, sogueros, cordeleros, etc.

-Señalábamos, más arriba, que la extracción social del inmigrante catalán era heterogénea, así pues, nos hallamos ante una serie de individuos pertenecientes a un relativamente elevado status social, como por ejemplo tenemos a hijos de médicos, farmacéuticos, y de notarios, que emigran a Cuba para dedicarse a la actividad comercial.

-Por último, debemos señalar que más del 50 por ciento de los emigrantes catalanes son hijos y nietos de comerciantes.

4. Como una característica más del fenómeno migratorio catalán a Cuba, hemos de señalar que, a groso modo, estamos ante el típico

(3) Ibídem. Páginas 27-28. 
fenómeno de emigración golondrina. Es muy frecuente el que un individuo posea un negocio en Cuba con uno, dos, o más socios, todos ellos catalanes, y el que exista un riguroso sistema de turnos para estar al frente de dicho negocio y para regresarse a España. Muchos emigraban sólo por 6 meses ó 1 año.

5. La emigración del comerciante catalán, generalmente se encuentra sustentada en una amplia malla de clientelismo y capital que ha sido labrada de generación en generación.

A continuación vamos a corroborar las características señaladas a través de ejemplos, basados en testimonios documentales seleccionados.

Licencia de Jaime Bonell Galup. Año de 1827. Este individuo era natural de Calella, de profesión comerciante, de 34 años de edad y de estado civil casado. Con el previo consentimiento de su esposa, desea emigrar a la ciudad de Matanzas a fin de incorporarse varios caudales que tiene en la misma, y continuar allí dedicado a su actividad comercial (4).

Hemos podido comprobar, según partida bautismal, que el padre de Jaime Bonell Galup era de profesión pescador. Esto nos ratifica en el ya, $\tan$ mencionado, trasvase generacional del Sector Primario al Terciario. Esta movilidad profesional es una vía de ascenso socio-económico.

Licencia de embarque de Bartolomé Busquets Plá. Año de 1827. Este era natural de Sitges, de 12 años de edad y soltero. Con el consentimiento materno solicita emigrar a Bayamo en donde su padre, Alejo Busquets, se encuentra establecido con tienda de comercio, y el padre la reclama para adiestrarle e incorporarle al mundo de los negocios (5).

El caso, que aquí reproducimos, es muy propio de la emigración adolescente catalana. Los padres suelen marchar a Cuba cuando los hijos son muy pequeños, y al despertar la pubertad en éstos son reclamados, a fin de que tenga continuidad, sentido y transcendencia el patrimonio paterno labrado en Ultramar.

(4) Licencia de embarque de Jaime Bonell Galup. Ultramar, 346. Archivo General de Indias.

(5) Licencia de embarque de Bartolomé Busquets Plá. Ultramar, 346. Archivo General de Indias. 
Licencia de embarque José Puig Cruañas. Este era natural de Santa Coloma de Fitor, en Gerona, de 22 años de edad, soltero, y de profesión droguero. Con el consentimiento paterno, solicita emigrar a La Habana para incorporarse a la casa de comercio de su paisano, Pedro Torruella, que lo reclama (6).

Por la partida bautismal del exponente, podemos conocer que su padre era labrador-propietario, lo cual nos corrobora una vez más, el paso generacional de la actividad agrícola a la comercial, paso que no sólo lo protagonizan los hijos de los labradores asalariados, sino también los hijos de labradores hacendados o propietarios, como es el caso que nos ocupa.

Licencia de embarque de Francisco Ferret Batllori y de Pelegrín Ferret Batllori, hermanos. Año de 1828. Estos individuos eran naturales de Sarriá, ambos eran albañiles, sus edades eran de 31 y 26 años respectivamente, el estado civil es el de solteros. Con el consentimiento paterno, el padre tenía la profesión de hacendado, desean marchar a La Habana para incorporarse varios caudales que tienen en la misma procedentes del comercio (7).

Este caso, que nos puede resultar curioso por ese juego y variedad de profesiones que concurren en un mismo individuo y en una misma familia, es común en la sociedad catalana, pues nos hallamos ante unas estructuras más dinámicas que las del resto de España, merced a la actividad comercial y a la existencia de una burguesía que propicia la movilidad social.

Licencia de embarque de Antonio Conchs Bonafé. Este individuo era natural de Arenys de Mar, de profesión mancebo, de 24 años de edad, soltero. Con el consentimiento de su padre, desea emigrar a La Habana para asociarse a la casa de comercio que allí tiene establecida su hermano, llamado Ramón Conchs Bonafé (8).

El padre del solicitante es notario de profesión. Con este caso ejemplificamos un fenómeno muy habitual en algunos catalanes que, procedentes de familias de status social relativamente elevado, tienen el gran valor y estima la actividad comercial.

Licencia de embarque de José Masó Capdet. Este era natural de San Pedro de las Ribas, comerciante, de 27 años, soltero. Con el

(6) Licencia de embarque de José Puig Cruañas. Archivo General de Indias. Ultramar, 348.

(7) Licencia de embarque de Fco. Ferret Batllori y Pelegrín Ferret Batllori. Archivo General de Indias. Ultramar, 349.

(8) Licencia de embarque de Antonio Conchs Bonafé. Archivo General de Indias. Ultramar, 350. 
consentimiento paterno, el padre es labrador de profesión, desea emigrar a La Habana, pues alli es reclamado por unos socios con los que comparte la casa de comercio, establecida en la citada ciudad bajo el nombre social de Masó Roig y Cía. (9).

Esta última licencia de embarque es un ejemplo típico de la emigración catalana a la Isla de Cuba, pues en él observamos.

-Por un lado, asociacionismo comercial y emigración golondrina.

-Por otro lado, el fenómeno migratorio sustentado por una amplia base de capital y clientela.

Podríamos traer a colación, y a modo de apéndice, incontables licencias de embarque de catalanes a la Isla de Cuba, pero creemos que con los ejemplos expuestos y las gráficas adjuntas contribuimos a dar una visión, más o menos, general del fenómeno migratorio catalán a la Isla de Cuba a comienzos del siglo XIX.

Para concluir, consideramos interesante referirnos a unas palabras de Carlos Martí sobre la impronta del emigrante catalán en Cuba durante la primera mitad del siglo XIX:

"Fue en esta época cuando el sentimiento cubano se exteriorizaba y en esta época que se creía a Cuba que era el Nuevo Eldorado al extremo de que había un modismo que decía que se encontraban las onzas de oro a puntapiés. También es la época de oro de la energía catalana a Cuba..., en todas las manifestaciones sociales se destaca un hijo de Cataluña.

En Santiago de Cuba, por ejemplo, los catalanes son comerciantes, bodegueros, industriales, verduleros, y no se les nombra por su oficio o giro, sino que a todo comerciante se le llama catalán, el catalán de la esquina, por ejemplo, pues las tiendas estaban en las esquinas. La mayoría son de catalames pero aún a los elementos de color establecidos con tienda abierta se les llama, por ej., "el negro catalán" (10).

(9) Licencia de embarque de José Masó Capdet. Archivo General de Indias. Ultramar, 341.

(10) MARTI, Carlos: LOS CATALANES EN AMERICA. CUBA. Editorial Minerva Biblioteca de Cultura Moderna y Contemporánea. Barcelona, 1918. Capítulo VIII. Páginas 151-152. 


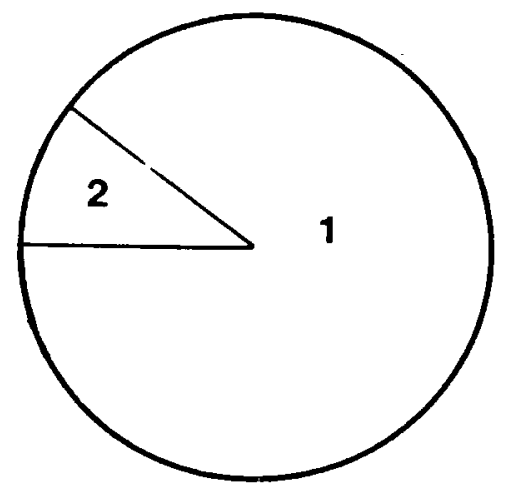

SEXO

1. Varones

2. Mujeres

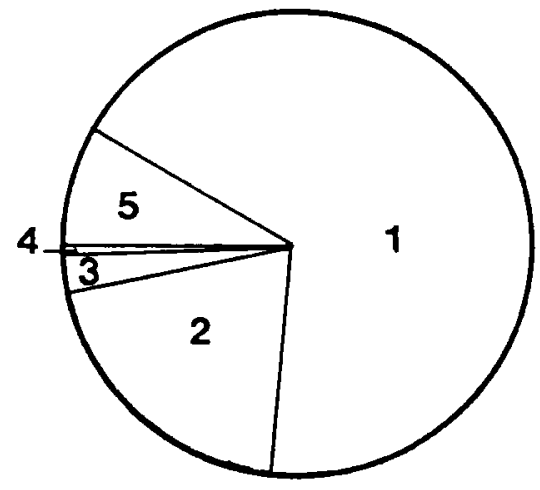

\section{ESTADO CIVIL}

1. Solteros

2. Casados

3. Viudos

4. Religiosos

5. Sin especificar

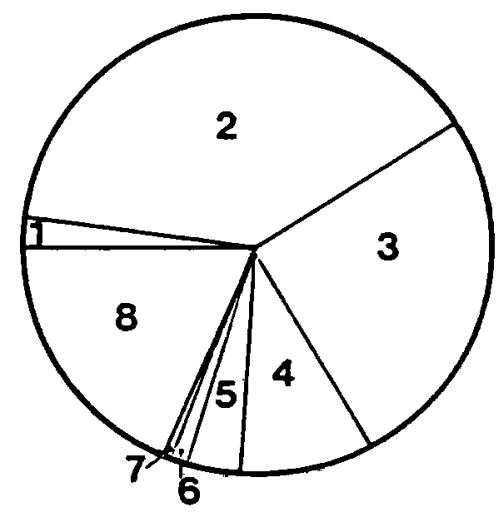

1. Menores de 10 años

2. De 10 a 20 años

3. De 21 a 30 años

4. De 31 a 40 años

5. De 41 a 50 años

6. De 51 a 60 años

7. Más de 60 años

8. Sin especificar

Gráfico 1: Emigración peninsular a Cuba (1800-1835). 


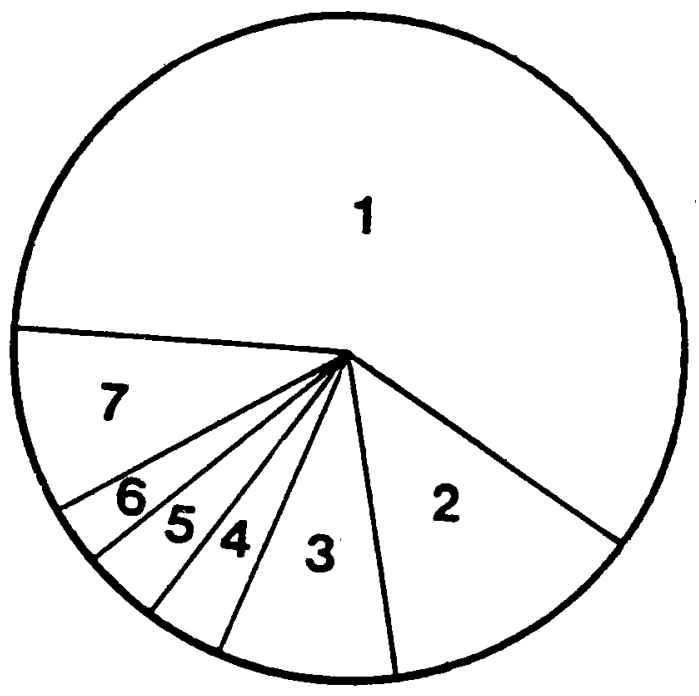

\section{REGION DE ORIGEN}

1. Cataluña

2. Asturias

3. Vascongadas

4. Navarra

5. Santander

6. Galicia

7. Otras regiones

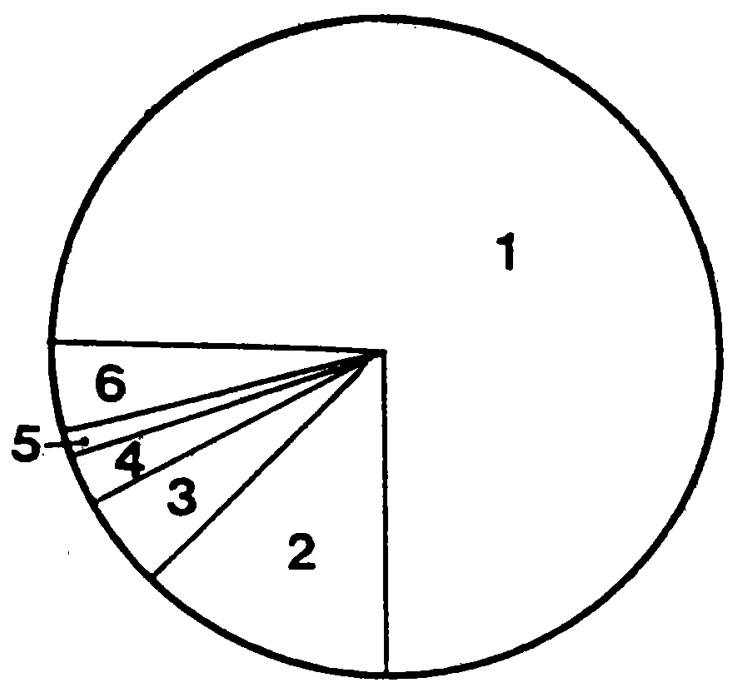

LUGAR DE DESTINO

1. Habana

2. Santiago

3. Matanzas

4. Puerto Príncipe

5. Bayamo

6. Otros lugares

Gráfico 2: Emigración peninsular a Cuba (1800-1835). 